the centre. The third screw is midway between the other two, and at the end of the plates.

Looking normally through the plates at the glowing filament of an incandescent lamp, a number of images of it will probably at first be seen. Adjust the pressure screws until these images are in juxtaposition in the line of sight; the silvered surfaces are then approximately parallel. Place the instrument in a clamp stand, and focus the light from a sodium flame or a vacuum tube upon the plates, and look at the interference bands with a small laboratory telescope focussed for infinity. Usually the eye-piece has too large a magnification for the above retardation, and it is better to use in place of it a single lens of focal length about 2 inches. At first only a small section of the interference pattern is seen, but with a little careful adjustment of the pressure screws the whole ring system is obtained in sharp focus. Removing the telescope, and with the above lens used as eye-piece, focus the interference system from the above sources, or an arc upon the slit of a spectroscope. The bands in the different spectrum lines are thus observed with the telescope on the spectrometer.

For further suggestions regarding the adjustments and other experiments for which this apparatus can be used reference may be made to an article by the writer in the Philosophical Magazine for May, I904.

Bryn Mawr College, Bryn Mawr, Pennsylvania.

\section{JAMES BARNes.}

\section{An Ornithological Coincidence.}

ON September 18, 1908, a fine, typical male of Anthus bertheloti, Bolle, the common Canary Islands pipit, was caught near Cremona, the first of its kind obtained in Italy. I received the interesting specimen " in the flesh." On March 16 of this year Mr. W. P. Pycraft presented at the meeting of the Zoological Society of London an account of the fossilised remains of a small Passerine bird from the "Gabbro" (Lower Pliocene) near Leghorn, which he identified as those of Berthelot's pipit (see NaTURE, p. IIg). The coincidence is certainly worth noting.

I may add that last autumn, during the later migrations, we had in Italy an unusual inflow of western species of birds, and amongst others and the above-mentioned pipit I received, also " in the flesh," a fine specimen of the large variety of the wheatear (Saxicola leucorrhoa, $\mathrm{Gm}$.), known to breed in Greenland and to migrate southwards along the extreme west of Europe into Senegal. The specimen, a female, is the first registered in Italy; it was captured, also near Cremona, on November 7 last.

HeNRY H, GIGLIOL.

Royal Zoological Museum, Florence, March 29.

\section{April Meteors.}

MoonLIGHT will not hinder observations of the Lyrids and other shooting stars in the latter part of April in the present year. The following are the principal meteor showers that become due during the period April I9-30. The times of the various meteoric events as calculated by the writer are expressed in Greenwich mean time.

Epoch April 19, 12h. Shower of eighth order of magnitude, the maxima of which occur on April 20 , 10h. $45 \mathrm{~m}$., $22 \mathrm{~h}$. 3om., and April 22, 6h. There is also another smaller shower connected with this having its maxima on April 20, I2h., April 21, 18h., and April 22, 7 h.

Epoch April 25, ih. This shower, which is of the thirteenth order of magnitude, has its principal maximum on April 27 , 14h. Secondary maxima take place on April 25, 14h. $30 \mathrm{~m}$. and $20 \mathrm{~h}$. $30 \mathrm{~m}$.

Epoch April 29, I8h. Shower of seventh order of magnitude. Its principal maximum occurs on April 27, 9h. $45 \mathrm{~m}$., and there are other maxima on April 27, 23h. 45m., and April 29, 3h.

From the foregoing it seems that meteors should be found especially numerous on the nights of April 20 and 27 . On the latter night there are two principal maxima occurring at times very suitable for observation.

April 12.

JOHN R. HENRY.

\section{THE GRAMOPHONE AS A PHONAUTOGRAPH.}

I $T$ is well known that during the last few years the gramophone (invented by Berliner in 1887), in its more complete and expensive forms, has been so much improved as to have completely eclipsed the phonograph. It is now an instrument that not only records pitch and intensity, but also quality to a surprising degree, so that one can listen to orchestral music in which the quality of each musical instrument is rendered with much fidelity, and also to the fine voices of many of the most celebrated vocalists of the day. Chorus effects are also remarkable, and one can, for example, enjoy the Soldiers' Chorus from Faust or the Wedding Chorus from Lohengrin. The nasal effects, the thin reediness of the voices, the alterations in quality, so characteristic of the phonograph, and of the gramophone in its earlier stages, have now almost entirely disappeared; indeed, it is no exaggeration to say that no scientific instruments have made greater progress since the inception of the phonograph a little more than thirty years ago.

Certain interesting data regarding the gramophone disk are worth recording. These I have determined on one of the smaller disks having a diameter of Io $\frac{1}{2}$ inches, with the record beginning $\frac{1}{2}$ inch from the margin. The record then traces its spiral groove until it is $2 \frac{1}{4}$ inches from the centre, so the record has a breadth of a little more than $2 \frac{3}{4}$ inches, or, say, 3 inches. The diameter at the beginning of the record is ro inches, in the middle 7 inches, and at the close of the spiral, towards the centre of the disk, 4 inches. Multiplying each by $3^{\circ}$ I 4 gives the circumterence of the circle as $3 \mathrm{r}_{4}^{\circ}$ inches, in the middle $21^{\circ} 98$ inches, and in the centre ${ }_{12}{ }^{\circ} 6$ inches, or, together, $65^{\circ} 94$ inches, giving a mean of $21^{\circ} 98$ inches, or, say, 22 inches. There are 100 grooves per inch from the centre towards the circumference; $100 \times 22=2200$ inches; the breadth of the record $=3$ inches; therefore $2200 \times 3=6600$ inches; or $55^{\circ}$ feet, or 183 yards, is the average length of the record groove. That is to say, in reproducing Waldenteufel's waltz, Estudiantina, the needle, in 205 seconds, ran over a distance of 550 feet. This gives a rate of $32 \%$ inches per second. With disks of a larger diameter, the length the groove in a long record may be more than 200 yards.

But when this record was reproduced (it is a remarkably good orchestral record) the disk travelled at the rate of 76 revolutions per minute, or $0^{\circ} 8$ second per revolution. At the beginning of the record, therefore, I inch was covered in $3 / 100$ second, at the middle in 4/roo second, and at the close of the record in $6 / 100$ sccond. In other words, the needle traverses a shorter and shorter distance, but in the same time, in passing from the circumference to the centre. Consequently there is no alteration in pitch. It follows also that, given vibrations of the same frequency for a note sounding at the beginning of the record and at the close, the marks of each vibration must be closer together at the centre than at the circumference. Thus, supposing a frequency of 200 per second, there would be about six vibrations in an inch at the beginning (outer circumference) and twelve in an inch at the end of the record (centre). A note of 1000 vibrations per second would have thirty in an inch at the beginning, and sixty in an inch at the close of the record. I was able substantially to verify this by placing the disk under a microscope, with a low power, and counting the number of marks in a lineal inch. This also gives a convenient method of determining the pitch of any note, provided one can count a sufficient number of marks

$$
\text { NO. 2059, VOL. 80] }
$$


in an inch, or in the fraction of an inch. Thus, suppose ten marks in one inch, then the frequency would be more than 3 oo vibrations per second. A difficulty arises when we find a complete vibratory period not represented by one wave, but possibly by three, one, the first, large, and the other two smaller. Then, to ascertain the real pitch, only the large marks must be counted.

Many attempts have been made to obtain an enlarged record of the wave-forms on the phonograph and gramophone, and much success was attained long ago by Fleeming Jenkin and Ewing, and, in later times, by Hermann, Scripture, and myself. Still, none of these were facsimile tracings. It seems to me that the gramophone, in its present condition, holds out the hope of an experimentalist being able to obtain from records tracings on a smoked glass circular plate travelling at the same rate as the record. Then, by placing the plate in a lantern, we should see a representation of the waves amplified, but amplified in all proportions. This I have succeeded in accomplishing, with a considerable measure of success, after a trial of a good many methods.

(I) Place a smoked glass plate, ro inches in diameter, with a hole in the centre, on the platform of the gramophone (the recording of waves on a smoked glass plate was a method employed by Berliner in his early experiments). As the swinging arm (or taper arm, as it is technically called) of the gramophone tends to swing outwards, and as the outer lip of the groove on the record tends to draw it inwards, and thus to follow the spiral, the needle, if placed on the smoked plate, will not move inwards. To overcome this I attached by a thread the swinging arm to a very slow-moving train of wheels, driven by an old phonograph, and thus I gradually drew the swinging arm inwards, so that a spiral was made on the smoked glass having a thread of about fifty to the inch. I was unable with my apparatus to obtain a slower motion. Then I removed from the gramophone the large horn, and sang, spoke, or shouted into the tube at the end of the swinging arm. The disk of the gramophone vibrated, and the needle described minute waves of various forms on the glass plate. I found, however, that when a cord connected the taper arms of the two gramophones there was not a continuous pull, but a rhthymic oscillation, producing a tracing showing light and dark bands, as the oscillations of the arms of the gramophones had not the same period. A beautiful tracing was thus obtained, showing, at regular distances, light bands owing to the lines becoming very close together, giving a figure such as one has seen for the illustration of waves of sound, or such as occurs in Crova's disks. By this method and the use of an eccentric arrangement, Crova's disks might be prepared. These light and dark bands were got rid of by connecting the arms of the two gramophones by a rigid rod. The finest gramophone needles were used for recording.

I also, by this method, caused a loud phonograph to act, by a connecting tube, on the mica disk of the gramophone, through the tube of the swinging arm, and I obtained tracings.

(2) Another method was unsuccessful, and had to be abandoned, both owing to difficulties of adjustment and because it gave incorrect results. It consists of elongating the vertical rod in the centre of the gramophone platform. A glass plate, smoked, is then fixed to the rod by passing the rod through a hole in the centre and through a collar, that can be clamped. The plate is of the same diameter as the gramophone disk record; it is smoked on its under surface, so that, when matters are adjusted, the disk of the gramophone is directed upwards and the smoked surface downwards, and about $2 \frac{3}{4}$ inches


hone disk showing the oscillatory periods of the taper

above the record. A firm upright bar of steel is soldered to the outer surface of the end of the spring attached to the needle of the sound-box, and this bar carries vertically a very fine needle. The point of this needle is brought with a minimum of friction against the under surface of the smoked disk. The gramophone is then started, and the platform with the central rod carries both the record disk and the smoked glass disk. The tracing so obtained was not satisfactory.

(3) I obtained the best tracings by causing one gramophone to sing or play at the usual rate, and, at the same time, by a rigid rod connecting the two arms, to draw towards itself the arm of a second gramophone on which was placed a circular smoked glass plate. The needle of the second gramophone described a spiral with intervals between successive spirals of $\mathrm{r} / \mathrm{IOO}$ inch, exactly similar to the spirals on the record of the first gramophone; but, before 
starting, the resonator of both gramophones was removed, and the circular openings at the base of each taper arm were connected by a wide tin tube. When the first gramophone acted the sound waves passed, not out by the resonator, as usual, but along the transverse tin tube to the other gramophone, the sound disk of which then vibrated and wrote the tracings on the blackened glass plate. This method, apparently so simple, gave rise to great

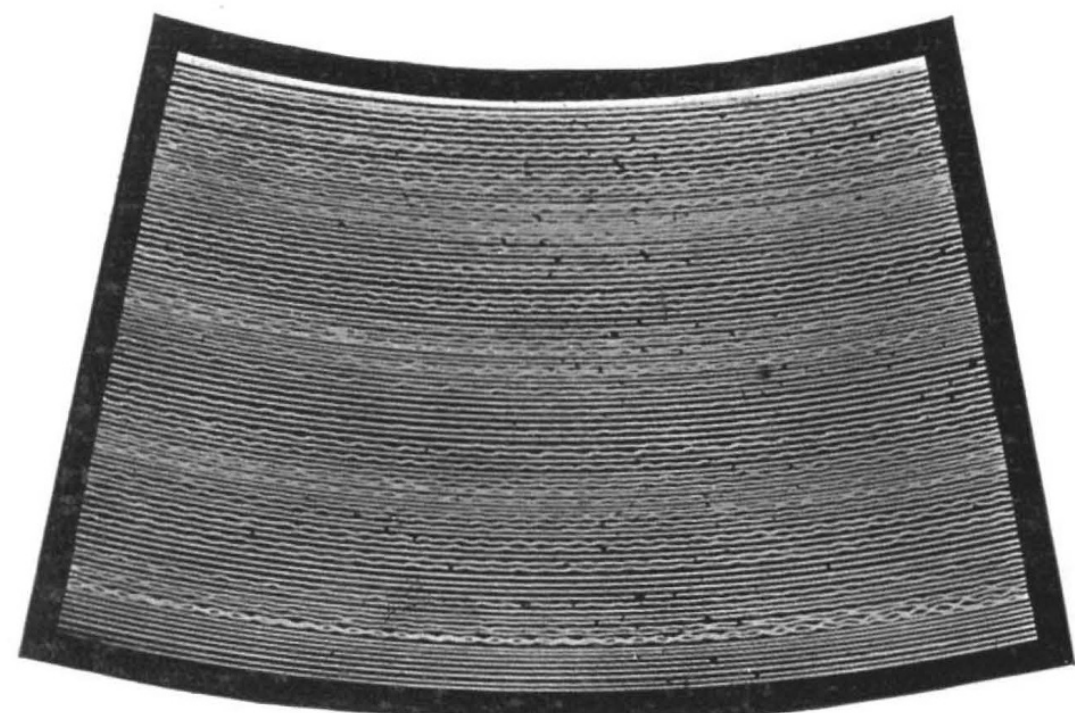

FIG. 2.-Portions of the record of a powerful bass voice (Oreste Luppi, of Milan) singing La Calunnia from Il Barbiere di Siviglia. Examine with mannifying glass.

gramophone operators, say, of the sounds of an orchestra, air currents carried the vibrations against the diaphram of the recording instrument with sufficient intensity to enable the recording needle to cut its way into the soft matrix employed; but the energy of tones coming from the sound-box of the reproducing gramophone (that is, the gramophone working on the disk) ${ }^{1}$ was, of course, very much diminished; still, sounds were heard (the drum-head was moved), although no movements of the disk of the second gramophone could, by the above method, be recorded. The amplitude of the movements of the drumhead must be inconceivably small, and yet they are sufficient to transmit pressures to the nerve terminations in the cochlea.

These experiments were made at home and without the appliances of a laboratory, and as, owing to circumstances, I cannot continue them, I will be glad if the method or methods above described are taken up by a younger worker. The sound waves may also be seen by the ingenious method of reflecting a beam of light from a small mirror attached to the diaphragm on to a revolving Wheatstone mirror. This method was invented by $\mathrm{Mr}$. Bowron. Several years ago Dr. James

trouble owing to the sound-box of the second gramophone being so heavy as to damp or obliterate many of the vibrations transmitted from the first gramophone. I substituted for the sound-box of the second gramophone (1) one of Pathe's simple reproducers, having, by a cork, a needle attached to the centre of the disk; (2) a very delicate tambour made by Albrecht, of Tübingen, used in Heurthle's ingenious arrangement for recording the sounds of the human heart; (3) one of Brodie's tambours, made by C. F. Palmer; and (4) a capsule, made by Joos, of Frankfort, for Marbe's method of recording the vibrations of König's flames. The first gave the best results, but was not quite satisfactory. Nos. 2,3 and 4 were of no service, as they were too mobile, and too susceptible of vibrations due to inertia. The same objection applied to the needle in No. I. After a great deal of trouble, however, I found the ordinary sound-box of the gramophone most effective after suspending it so as to remove weight, and so as to allow the needle to touch the smoked glass plate with a minimum of friction. In these experiments one had a striking illustration of the delicacy of the movements of the drum-head of the ear. The more delicate tones, or, rather, the weaker tones of a fine voice, on which expression so much depends, were not recorded by any of my mechanical appliances, and only foad, strong, rich tones (like those of a powerful orchestta) left their traces. When the record was made by the
Erskine Murray showed me an arrangement of his own of a similar kind.

(4) The gramophone is an excellent phonautograph. Take two gramophones; one to draw the needle over the smoked glass plate on a second gramophone; remove the resonator of the second gramophone; suspend the sounding box of the second gramophone until the needle barely touches the smoked glass plate; and then, through a wide tin



Fig. 3.-Record of vibrations of human voice, in the experiment of using the gramophone as a phonau. tograph. Examine with magnifying glass.

tube, having a diameter the same as that of the opening at the end of the taper arm of the second gramophone, speak or sing into the second gramophone. Thus the vibrations are recorded, while the speed of the smoked glass plate is known. Long ago I traced vowel curves and other sounds (using a phonograph recorder) on a vertical smoked glass plate moving

1 For an account of the gramophone see an interesting paper by Lovell N. Reddie, read before the Ro yal Society of Arts, May 6, 1908. 
rapidly horizontally, but by this method I could only record in each experiment during the time of the movement of the glass plate-about one second. By the gramophone, records of vocal sounds might be taken during a period of three minutes.

An inspection of the curves so obtained of a voice or of an orchestra only makes the performance of a gramophone more wonderful and more difficult to understand. We see a long series of waves of various forms which the eye cannot follow; but when these waves appeal to the ear, then music starts into life. Each sense has its own beat.

\section{JOHN G. MCKENDRICK.}

\section{THE POISONS OF THE PHARMACY ACT.}

$\mathrm{NE}$ of the minor legislative achievements of last session was an amendment of the Poisons and Pharmacy Acts. So far as poisons are concerned, tit may be noted that these Acts restrict the facilities for obtaining certain substances which experience has shown to be often responsible for fatalities, whether by accident or by intentional administration. Besides the commoner violent poisons-the arsenic and strychnine of the wilful poisoner, the prussic acid and carbolic acid of the suicide-there are milder varieties of toxic substances which may lead to fatal results through ignorant or careless usage, and which should therefore not lightly be dealt out to ignorant or careless users. Such, for instance, are the narcotics, as morphine and sulphonal; the emetics, e.g. tartar emetic; and the abortifacients, such as ergot and savin.

What is a poison? Precise definition is difficult. Very largely it is a matter of quantity; most medicines are poisonous if taken in excess. Personal idiosyncracy and immunisation are also factors. The proverb "One man's meat is another man's poison" contains at least the half-truth characteristic of proverbs; and the Styrian arsenic-eaters, as Sir Henry Roscoe showed nearly fifty years ago, can easily withstand doses of arsenic which would be fatal to ordinary people.

In the Act before us the legislature defines its poisons by enumerating them. To toxicologists and pharmacists the list is no doubt familiar enough. To other readers, however, it may be of interest to glance at the list of articles now included in the schedule of poisons. These, as explained below, are only to be sold under certain specified conditions.

Part $i$. of the schedule is concerned generally with the more active poisons, upon the sale of which the more stringent restrictions are naturally placed. The buyer must be known to the seller, or must be introduced to him by a third person known to both; the sale must be recorded in a special book and the entry signed by the purchaser, and the purpose for which the drug is required must be stated.

Arsenic; alkaloids, and the poisonous cyanides form most of this first division. Several of the alkaloidsaconite, aconitine, atropine, belladonna, strychnine, and morphine-are specifically named; but there is also a general category of " all poisonous vegetable alkaloids," which brit:gs in any not otherwise enumerated. Coca, cantharides, corrosive sublimate, tartar emetic, ergot, picrotoxin, and savin complete the list as regards part $i$.

Part ii. of the schedule contains a list of articles which (I) are to be sold only by registered chemists, and (2) must be labelled as poisons when sold. It includes oil of almonds (unless deprived of prussic acid), antimonial wine, carbolic acid and its homologues, chloral, chloroform, digitalis, the iodide, sulphocyanide, chloride, and oxides of mercury; poppies, strophanthus and sulphonal, together with all preparations which contain a poison within the meaning of the Pharmacy Acts and are not otherwise dealt with.

Most of the foregoing articles are well-known poisons, and the reasons for including them are, perhaps, sufficiently obvious. But a few notes upon the less familiar of them may not be without interest.

One of the most noteworthy is the drug coca. This, the source of the alkaloid cocaine, consists of the dried leaves of Erythroxylon coca, a shrub which flourishes on the slopes of the Andes. It, has been used as a nerve stimulant by the Peruvian and Bolivian natives from time immemorial. Furnished with a smail stock of the leaves to chew, they will work or travel without food from morning until night. As there is no appreciable amount of nourishment in the leaves, the sustaining effect is regarded as probably due to the nerves of the stomach being locally benumbed by the drug, thus preventing the feeling of hunger. Although habitual excessive use of coca brings on insomnia, dropsy, and death, yet a single large dose is said, in the case of the natives, to give a sensation of peculiar physical beatitude. Joyous visions and brilliant phantasmagoria are recorded as the result of a very large dose in one case. On Europeans, however, the action appears to be curiously different from this, fear and terror rather than joy having been noted in numerous cases of coca poisoning.

Cantharides, the Spanish blistering fly, is the dried beetle Cantharis vesicatoria. It comes chiefly from Spain, Italy, and Russia. Internally, the drug acts as a powerful irritant, with a peculiar direction to the urinary and genital organs; externally it is used as a blister and rubefacient.

Ergot is the sclerotium of a fungus, Claviceps purpurea, arising in the ovary of the rye plant. It is scarcely a poison in the ordinary sense of the word, as most persons - the exceptions being women in pregnancy--can take large doses without fatal effect. Nevertheless, epidemics of poisoning on the Continent have been ascribed to the use of rye-bread contaminated with the fungus. Medicinally it produces contraction of those muscles which act involuntarily, and slows down the action of the heart.

A poison which is said to have been used as a hop. substitute in malt liquors has a place in the schedule. It is picrotoxin, a bitter, crystalline substance obtained from the berries of Cocculus indicus (Anamirta paniculata). The drug is a potent poison, producing convulsions and violent peristalsis. Savin has been much used in uterine affections. It consists of the dried tops of the shrub Juniperus sabina, Lin., a native of southern Europe and the United States. The volatile " oil of savin" obtained from it is a powerful local irritant which has been employed, often with fatal results, in producing criminal abortion. Strophanthus, the seeds of $S$. Kombe, is notable as the source of the Kombé arrow-poisorr, used in Senegambia, Guinea, and other parts of Africa. For the rest, space allows only a brief mention of sulphonal, which is a soporific drug (dimethyl-methane-diethyl sulphone) synthesised from acetone and mercaptan. Its narcotic action is usually quiet, without disagreeable after-effects; but chronic poisoning and fatal results have frequently accrued from long-continued and injudicious use of the drug.

A large number of deaths by accident and suicide are yearly attributable to poisoning by mineral acids. Restrictions are therefore now placed by the Act upon the sale of hydrochloric, sulphuric and nitric acids, as also of soluble oxalates. These articles must be 